\title{
Genomic characterization of the conditionally dispensable chromosome in Alternaria arborescens provides evidence for horizontal gene transfer
}

\author{
Jinnan $\mathrm{Hu}^{1}$, Chenxi Chen ${ }^{1}$, Tobin Peever ${ }^{2}, \mathrm{Ha} \mathrm{Dang}^{3}$, Christopher Lawrence ${ }^{3}$ and Thomas Mitchell ${ }^{1 *}$
}

\begin{abstract}
Background: Fungal plant pathogens cause serious agricultural losses worldwide. Alternaria arborescens is a major pathogen of tomato, with its virulence determined by the presence of a conditionally dispensable chromosome (CDC) carrying host-specific toxin genes. Genes encoding these toxins are well-studied, however the genomic content and organization of the CDC is not known.

Results: To gain a richer understanding of the molecular determinants of virulence and the evolution of pathogenicity, we performed whole genome sequencing of A. arborescens. Here we present the de-novo assembly of the CDC and its predicted gene content. Also presented is hybridization data validating the CDC assembly. Predicted genes were functionally annotated through BLAST. Gene ontology terms were assigned, and conserved domains were identified. Differences in nucleotide usage were found between CDC genes and those on the essential chromosome (EC), including GC3-content, codon usage bias, and repeat region load. Genes carrying PKS and NRPS domains were identified in clusters on the CDC and evidence supporting the origin of the CDC through horizontal transfer from an unrelated fungus was found.
\end{abstract}

Conclusions: We provide evidence supporting the hypothesis that the CDC in A. arborescens was acquired through horizontal transfer, likely from an unrelated fungus. We also identified several predicted CDC genes under positive selection that may serve as candidate virulence factors.

Keywords: Alternaria arborescens, Illumina sequencing, Conditionally dispensable chromosome, Horizontal gene transfer, Polyketide synthase, Host specific toxins

\section{Background}

The rapid development of next-generation sequencing technologies over the past decade has led to a flood of both de-novo sequencing and re-sequencing projects in almost every branch of the tree of life. Within the fungal kingdom, comparative genome studies have led to the unexpected finding that large genomic regions may be variable among isolates of a given species. One category of these variable regions are unique chromosomes referred to as supernumerary or conditionally dispensable because they are not typically required for saprophytic growth [1-3]. These chromosomes have been identified in many fungi including Magnaporthe oryzae [4-6],

\footnotetext{
* Correspondence: Mitchell.815@osu.edu

${ }^{1}$ Department of Plant Pathology, The Ohio State University, Columbus, OH 43210, USA

Full list of author information is available at the end of the article
}

Fusarium oxysporum [7], Nectria haematococca [8,9], Mycosphaerella graminicola [10], Cochliobolus heterostrophus [11], Leptosphaeria maculans [12], and Alternaria alternata $[13,14]$.

Plant pathogenic fungi in the genus Alternaria infect a remarkable range of host plants and are major causes of agricultural yield losses [15]. Conditionally dispensable chromosomes (CDCs) are carried by several of the small-spored, plant-pathogenic Alternaria species $[13,14,16]$. These chromosomes are generally less than $2.0 \mathrm{MB}$ in size, and may be transmitted horizontally between isolates in a population, potentially conferring new pathogenic attributes to the receiving isolate [17-20]. Loss of the CDC can also occur during repeated subculturing, resulting in the transition from a pathogenic to saprophytic form of the fungus [13]. Several genes coding host specific toxins (HSTs) have been located to gene 
clusters on CDCs, including those producing AF-toxin from the strawberry pathotype [21], AK-toxin from the Japanese pear pathotype [22], and ACT-toxin from the tangerine pathotype [23]. These toxins share a common 9,10-epoxy-8-hydroxy-9-methyl-decatrienoic acid structural moiety, with the genes encoding each toxin sharing a high degree of homology [21-25]. In addition, the AMT gene from the apple pathotype, a gene involved in host-specific AM-toxin cyclic peptide biosynthesis, is located on a small chromosome of 1.1 to $1.7 \mathrm{Mb}[13,26]$, with at least four copies involved in AM-toxin biosynthesis [27]. The only other gene sequences identified to date on CDCs are extended families of transposon-like sequences (TLSs) [14].

Horizontal gene transfer (HGT) is the movement, without recombination, of stable genetic material between two individuals [28]. HGT may not only occur between different individuals of the same species, but also between species or even between bacteria and fungi or between fungi and oomycetes [29,30]. In fungi, the movement of plasmids, mycoviruses, transposable elements, gene clusters, and whole chromosomes have been demonstrated from one individual to another [31]. The first theory to explain gain and loss of HSTs was proposed in 1983 [32]. It has then been hypothesized that the genome content of CDCs in Alternaria species were acquired through HGT events [14]. The most well studied example of HGT in fungi is the movement of the ToxA gene from the wheat blotch pathogen Stagonospora nodorum to Pyrenophora tritici-repentis, the causal agent of tan spot of wheat $[33,34]$. This horizontal transfer event was identified by nucleotide sequence similarity and structural comparisons between genes from both species. The direction of transfer was inferred by the fact that the ToxA gene consisted of a single haplotype in $P$. tritici-repentis but 11 haplotypes in $S$. nodorum isolates.

Alternaria arborescens (synonym A. alternata f. sp. lycopersici), the fungus that produces host-specific AAL toxin, is the causal agent of stem canker of tomato $[35,36]$. It has been observed in pulsed field gel electrophoresis (PFGE) studies that $A$. arborescens carries one $\mathrm{CDC}$ of $1.0-\mathrm{Mb}[16,37]$. To date, only two genes have been reported to be carried on this CDC including ALT1, which is a PKS gene involved in AAL toxin biosynthesis [38,39], and AaMSAS, also a PKS gene $[40,41]$. A CDC deletion mutant of $A$. arborescens generated through restriction enzyme mediated integration (REMI) showed a toxin and pathogenicity minus phenotype [41]. In addition, in protoplast fusion experiments, a CDC from $A$. arborescens was observed to transfer into the strawberry pathotype, and subsequently introduced new tomato pathogenicity to the fusant [41].

In this study, we used a next generation sequencing approach to produce a draft sequence of the $A$. arborescens genome and used a novel bioinformatics approach to separate CDC contigs from the essential chromosome (EC) contigs. The gene content of the CDC was analyzed to answer the following questions: (1) What is the difference between the $\mathrm{CDC}$ and $\mathrm{EC}$ genome content at the nucleotide level? (2) Are CDC genes under positive selection and could they represent additional virulence factors in addition to the known toxin encoding genes? (3) Is the evolutionary history of the CDC the same as that of the ECs, and is there any evidence of a HGT event? In answering these questions, we confirmed a different genome content pattern of the A. arborescens CDC and found evidence for HGT.

\section{Results}

\section{Sequencing \& assembly}

A. arborescens strain EGS 39-128 (CBS 102605) [42] was sequenced by a whole genome shotgun approach using the Illumina Genome Analyzer II, which resulted in 50 million paired-end short reads of 75 bp representing 90X average coverage of the predicted genome content. De-novo assembly was performed using Velvet [43] (version 0.7), and confirmed by Edena [44] and Minimus2 [45]. The assembly resulted in 1,332 contigs with a $\mathrm{N} 50$ of $624 \mathrm{~KB}$ and total size of $34.0 \mathrm{MB}$ (Additional file 1: Table S1; Assembly has been deposited at DDBJ/ EMBL/GenBank under the accession AIIC00000000. The version described in this paper is the first version, AIIC01000000.) One hundred thirty-seven large contigs with lengths greater than $10 \mathrm{~KB}$ and representing $98 \%$ of the genome assembly content were chosen for further analysis.

\section{Marker-assisted identification of contigs carrying toxin biosynthetic genes}

The first challenge in analyzing the $\mathrm{CDC}$ was to isolate its assembly contigs away from EC contigs. For this genome, the process was made more challenging as there is no defined reference genome, few genetic markers, and no optical map. It is known from previous studies that most Alternaria species, including the isolate used in this study, have a single CDC $[16,37]$. To begin assembly of the this chromosome, two previously identified CDC genes that belong to the toxin biosynthetic cluster, ALT1 and AaMSAS [38,40], were used as markers to search in all contigs. Through this strategy, two putative CDC contigs of $15 \mathrm{~KB}$ and $48 \mathrm{~KB}$ in length were identified as containing ALT1 and AaMSAS, respectively. These two contigs were annotated to identify PKS genes, other toxin biosynthetic genes, as well as genes with orthologs in other fungi and bacteria (Figure 1). Multiple putative HST genes were identified on both contigs, consistent with predictions based on previous reports [14]. 


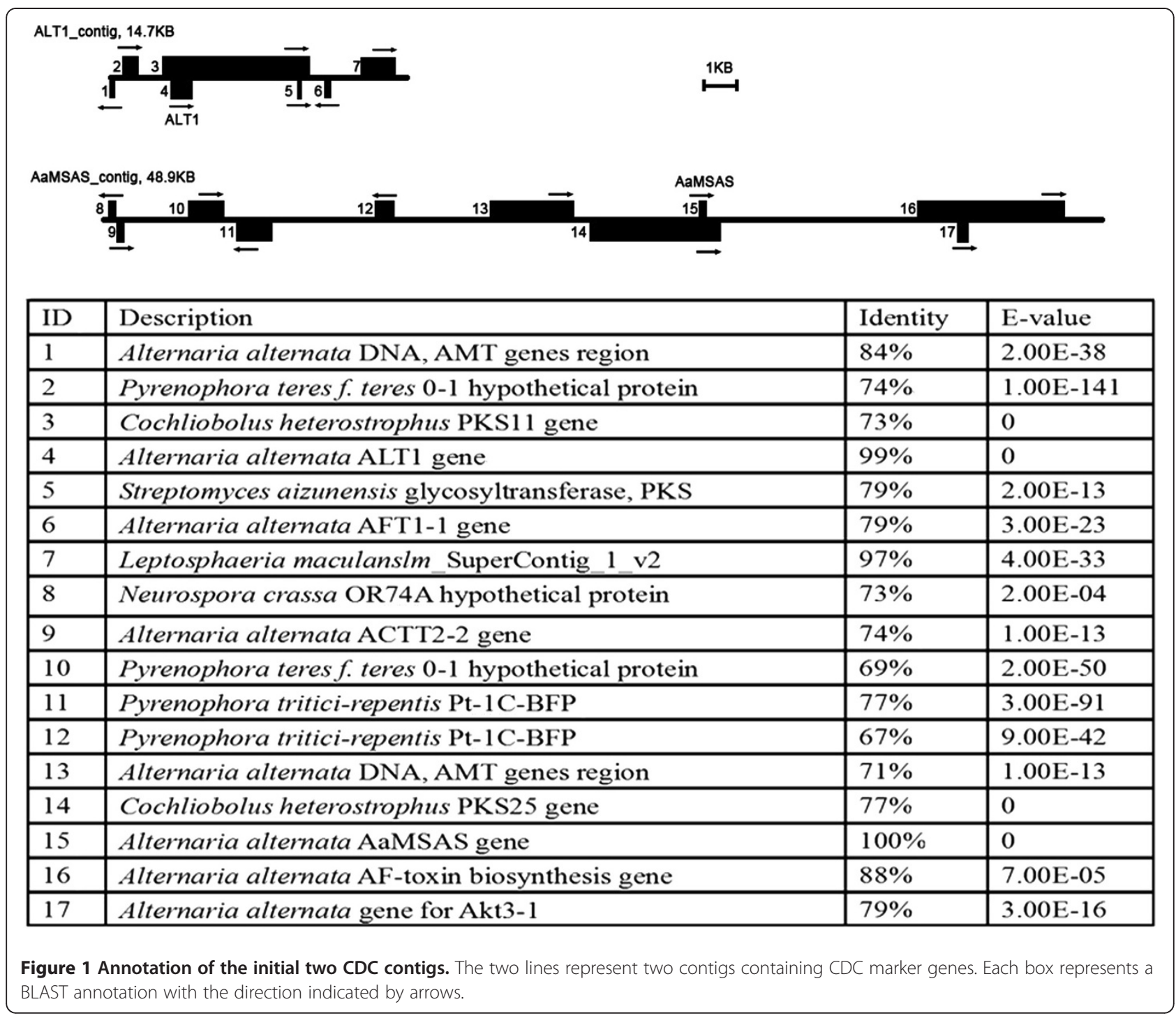

Identification of the remaining CDC contigs and validation by Southern hybridization

To identify additional CDC contigs, the Alternaria brassicicola $(A b)$ genome sequence was used as a reference (downloaded from The Genome Institute at Washington University). A. brassicicola is a related species to $A$. arborescens $(A a)$ but does not carry CDCs. All contigs from $A a$ were aligned to $A b$ contigs using MUMmer [46] as the alignment tool with an identity cut-off at $90 \%$. Eight previously identified marker genes from $A a, 6$ from the EC and 2 from CDC, were used to set criteria to distinguish contigs belonging to CDCs versus ECs [41]. (Table 1) After comparing the alignments of contigs containing the 8 marker genes, we set a CDC contig cut-off as those contigs with less than $20 \%$ coverage of sequence aligned to $A b$ with higher than $90 \%$ identity (including both coding and non-coding regions). Through this method, 29 predicted CDC contigs were identified with total length of $1.0 \mathrm{Mb}$, the same as the expected size from clamped homogenous electric fields (CHEF) gel analysis [16,37] (Figure 2A). The remaining 108 contigs were considered essential chromosomes (ECs) with total genome size of $32.3 \mathrm{MB}$ (Additional file 2: Figure $\mathrm{S} 1$ ). Validation that the selected contigs belong to the CDC was performed by Southern hybridization using genes predicted to reside on the $\mathrm{CDC}$ and $\mathrm{EC}$ contigs respectively as probes (Figure $2 \mathrm{C}-\mathrm{F}$ ). Five probes were hybridized including 4 from the CDC and 1 from the EC. Each probe gene is predicted to be present in a single copy. The first probe was ALT1, a toxin gene known to reside on the CDC [41]. This was followed by hybridizing with three CDC genes predicted from the de-novo assembly, including a transporter CDC_92, a polysaccharide export protein CDC_102, and an o-methyltransferase CDC_147. The fifth probe 
Table 1 Alignment of $A$. arborescens marker gene contigs and A. brassicicola contigs

\begin{tabular}{lllll}
\hline Contig ID & Length $(\mathbf{b p})$ & Alignment coverage & Marker gene & New ID \\
\hline NODE_9 & 48862 & $13.6 \%$ & AaMSAS & CDC_contig_23 \\
NODE_136 & 14729 & $15.7 \%$ & ALT1 & CDC_contig_27 \\
NODE_758 & 174048 & $26.1 \%$ & AKS17 & EC_contig_009 \\
NODE_8 & 199480 & $44.1 \%$ & AKS21 & $51.942 \%$ \\
NODE_58 & 833831 & $61.9 \%$ & MAT1-2-1 & EC_contig_038 \\
NODE_82 & 1201916 & $69.9 \%$ & ALM & EC_contig_063 \\
NODE_274 & 1472031 & $72.1 \%$ & VKS2 & EC_contig_085 \\
NODE_151 & 812677 & $73.5 \%$ & AaTUB & EC_contig_091
\end{tabular}

The first two contigs contain two CDC marker genes and the following six contigs contain six EC marker genes.

was EC_97_90_g721, a gene annotated as PKS and predicted to reside on the ECs.

\section{Gene prediction, length, GC3-content, and repeat identification}

Nine thousand, one hundred sixty-seven genes were predicted by FGENESH [47] using pre-trained Alternaria parameters, of which 209 genes were assigned to CDC contigs and 8958 to EC contigs. The average length of each predicted gene was $1.8 \mathrm{~KB}$, and the gene density was $3.7 \mathrm{~KB}$ per gene. Compared to gene predictions for A. brassicicola (average gene length $=1.3 \mathrm{~KB}$, gene density $=3.0 \mathrm{~KB}$ per gene), $A$. arborescens genes were longer and present in lower density. To evaluate the origin of the $C D C$, the predicted genes residing on the CDC and EC contigs were compared at the nucleotide level, including gene length, GC3-content [48], repeat load, and codon usage bias. This analysis showed that CDC genes are about 200bp shorter on average than EC genes $(P=2.36 \mathrm{E}-09)$ and have significantly lower GC3content $(P=0.028)$. Repeat regions composed $5.3 \%$ of CDC contigs while only $0.6 \%$ of EC contigs (Additional file 1: Table S2). It should be noted that some repeat regions could be lost in short read sequences de-novo assemblies, however, even with possible suppressed numbers, this result indicates approximately $10 \mathrm{X}$ repeat enrichment in the CDC compared to the EC.

\section{Codon usage analysis}

Codon usage comparisons of CDC and EC genes were used to determine whether a bias in codon usage exists between the two groups. Both the Codon Adaptation Index [49] (CAI, $P=0$, Figure 3) and Relative Synonymous Codon Usage (RSCU) [50] correlation ( $P=1.14 \mathrm{E}-14$,

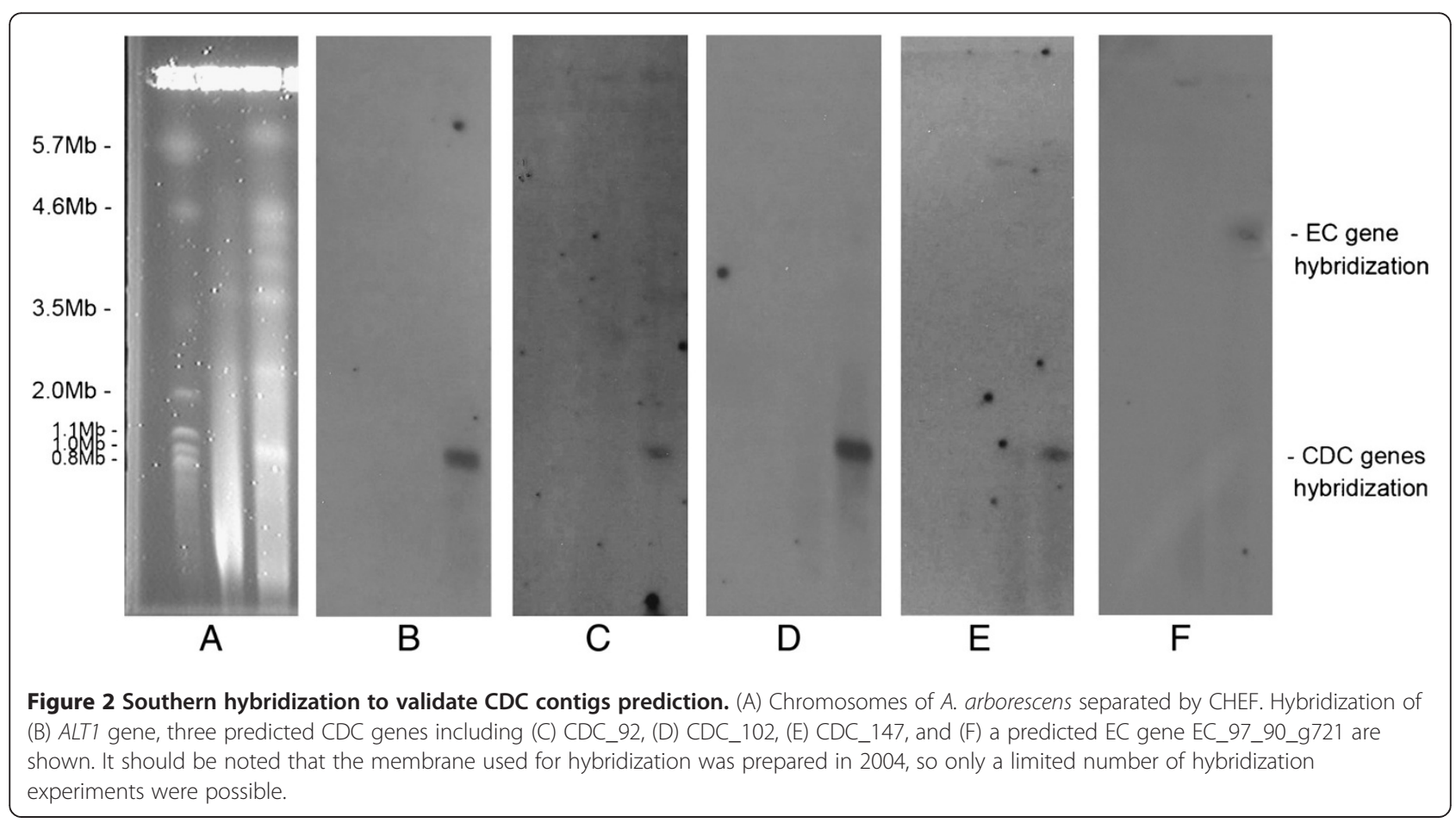




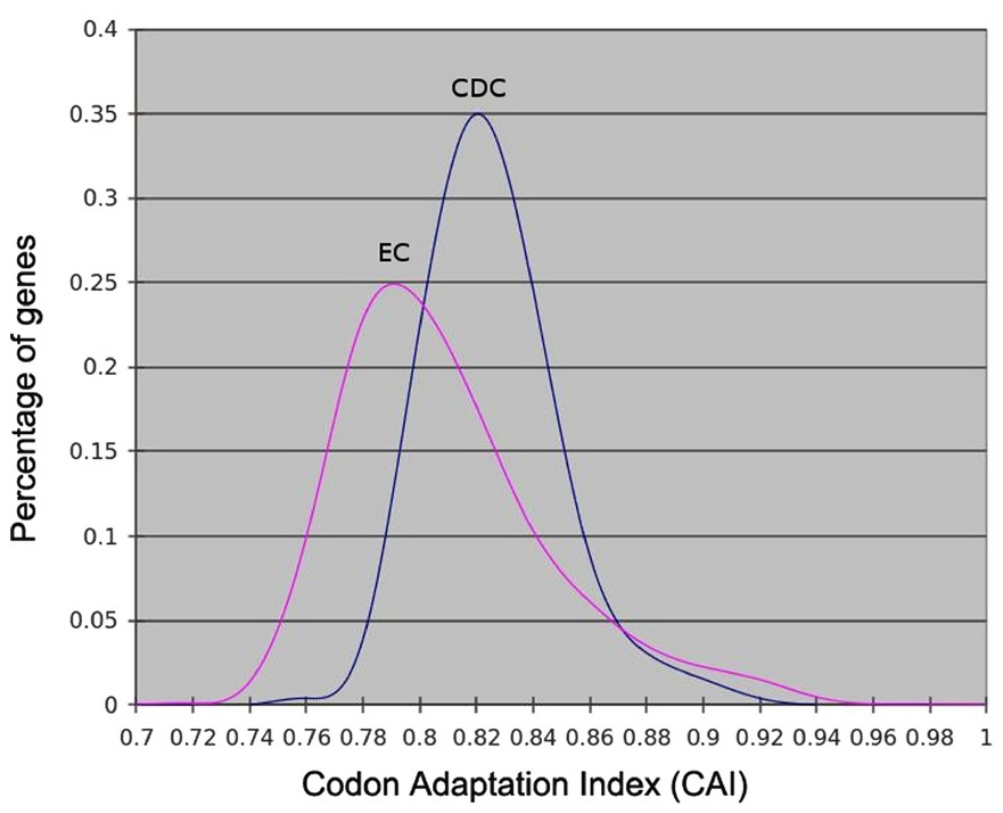

Figure 3 The Codon Adaptation Index (CAI) distribution of A. arborescens CDC genes compared to EC genes. The CAI derived from the RSCU estimations was computed using "Automated Codon Usage Analysis Software" (ACUA).

Additional file 1: Table S3) from the two groups were significantly different, suggesting a different origin. The largest codon usage bias was observed for the amino acids Tyrosine, Lysine, and Asparagine, with a preference for A over $\mathrm{G}$ and $\mathrm{T}$ over $\mathrm{C}$ in $\mathrm{CDC}$ genes (Additional file 1: Table S4). These three amino acids were not biased for CDCs in Fusarium [7], indicating there's no universal CDC codon usage bias pattern between Alternaria and Fusarium.

\section{Annotation of EC genes}

The assembly results showed the size of essential chromosomes region collectively to be $33.0 \mathrm{MB}$ with 8958 predicted genes. RepeatMasker identied only $0.12 \%$ of the EC region as simple repeats (about 50bp in length) and $0.08 \%$ as low complexity, indicating that short repeats may be lost during de novo assembly of Illumina sequencing reads. For secreted protein identification, 1099 (12.2\%) of the EC proteins were predicted to contain signal peptides, and were functionally annotated using BLAST to the NCBI database with more than $98 \%$ of the genes returning at least one hit with an E-value $<1.0 \mathrm{E}-3$. From the BLAST results, we identified 212 transcription factors, 98 oxidase proteins, 202 kinase proteins, 279 transporters, 81 Cytochrome P450s, and 45 different proteases.

\section{Annotation of CDC genes}

Several host-specific toxin genes and transposon-like sequences have been reported to be carried by CDCs in Alternaria [14]. We used two methods to annotate the functions of resident CDC genes: (1) they were blasted against the NCBI non-redundant database as well as Pfam [51] and NCBI CDD [52] to search for functional domains; (2) they were scanned to identify transcription factors, PKS genes, NRPS genes, P450s, transporters, and pathogenicity related genes.

From 160 NCBI BLASTN hits of putative CDC genes (Figure 4), the top five species matches were Pyrenophora teres, Pyrenophora tritici-repentis, Phaeosphaeria nodorum, Leptosphaeria maculans, and Nectria haematococca, all of which are fungal phytopathogens. Interestingly, A. alternata was ranked $7^{\text {th }}$ in this list, demonstrating that CDC genes were more similar to genes present in other fungal species rather than other Alternaria spp. Moreover, besides N. haematococca, all these other fungi are closely related taxonomically belonging to the class, Dothideomycetes.

Gene ontology terms were assigned to CDC genes based on BLAST matches with sequences whose function was previously characterized [53]. Ninety CDC genes were assigned to a biological process, 51 for molecular function, and 15 for cellular component (Additional file 2: Figure S2). Among the biological process assignments, $54 \%$ of genes were assigned to "metabolic process", and 10\% to "biosynthetic process". Enrichment of metabolic and biosynthetic process in CDC genes as compared to EC genes supported the observation that Alternaria CDC genes were enriched for polyketide synthases (PKS) and toxin synthases. Molecular function terms showed a significant 


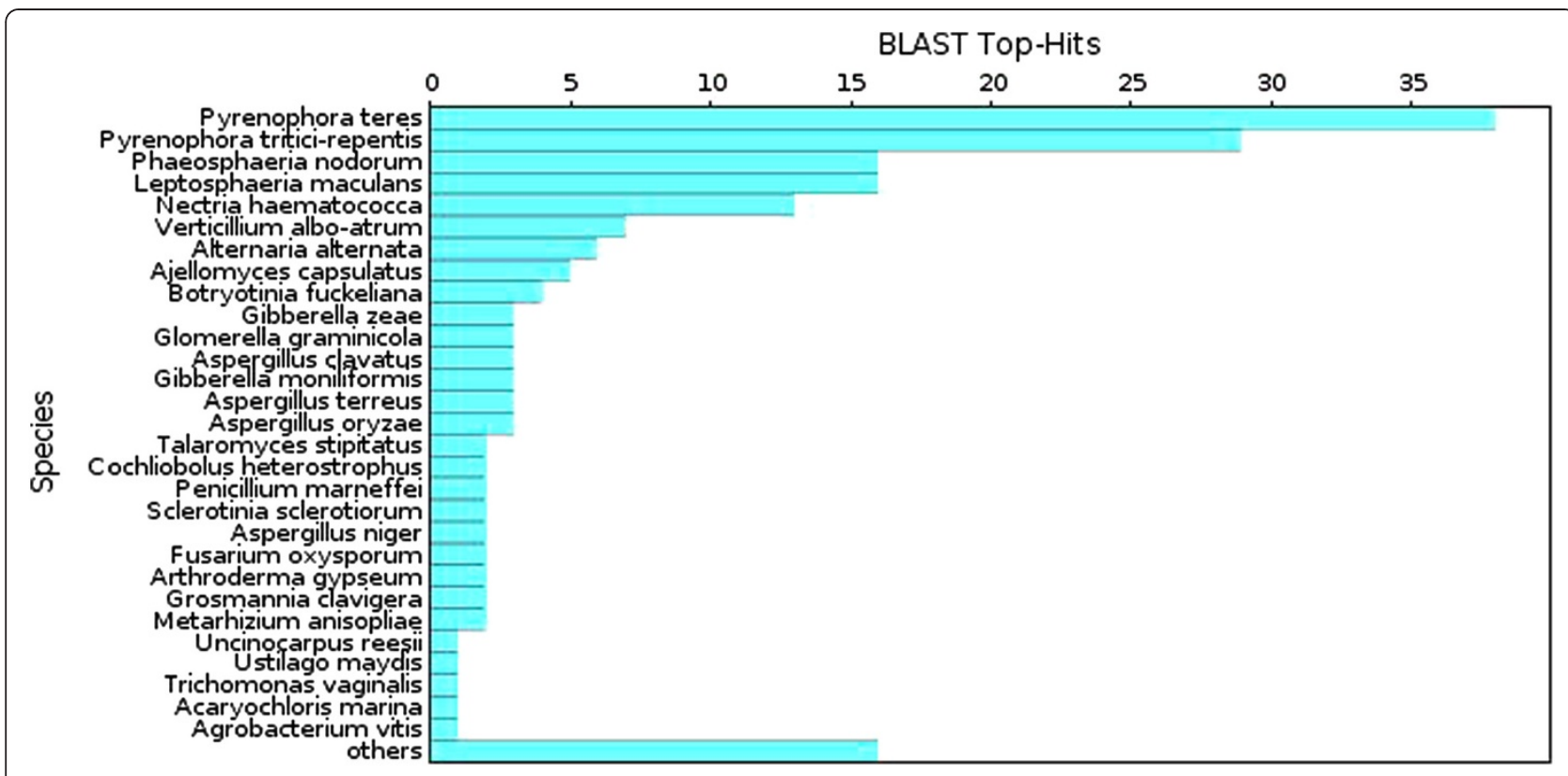

Figure 4 BLAST taxonomy report of all CDC genes against NCBI "Nucleotide collection (nr/nt)" database. Species of BLAST hits (E-value $<1.0 \mathrm{E}-3$ ) were ranked by their occurrence.

percentage (39\%) to "nucleotide/nucleic acid binding", which showed an enrichment of transcription factors and gene regulation elements.

To provide a more detailed characterization of putative CDC genes, each was translated to identify protein families. Among the 209 predicted CDC proteins, 31 were identified as carrying PKS domains. Two proteins were found to carry highly modular domains: KS-AT-KR-ACP on CDC_141 and KS-AT-DH-ER-KR-ACP on CDC_165. The remaining 29 PKS proteins each carried 1 or 2 ACPs (Acyl carrier protein) domains. Seven proteins were found to carry NRPS domains: 3 Enterobactin domains, 2 Bacitrancin domains, 1 Pyochelin domain, and 1 CDA1 domain. Two proteins were identified as hybrid PKS-NRPS. Seven proteins were identified as $\mathrm{P} 450$ monooxygenase proteins. For transcription factors, 24 proteins were characterized to contain TF domains, in which Zn2Cys6 was the prominent group. Multiple ADP/ATP transporters, ABC transporters, ion transporters and major facilitator superfamily (MFS) transporters were also found in CDC protein group. Additionally, it was found that multiple proteins carrying FAD binding domains and oxidoreductases. Finally, 37 proteins were identified as putative pathogenicity related genes through scanning CDC genes in the pathogen-host interactions database (PHI-base) [54] (E-value $<0.05)$. See Additional file 3 for a complete CDC gene annotation list.

\section{Secondary metabolite biosynthetic gene clusters}

In fungi, it has been reported that genes responsible for secondary metabolite biosynthesis (SMB) may be clustered $[4,55]$. Typically these include PKS or NRPS genes, as well as genes responsible for structural modifications of initial metabolites, for transport, and for transcription regulation [56]. In this study, we screened each CDC gene and those surrounding them, looking for evidence of clustering of PKS, NRPS, transcription factors, transporters, P450 proteins, FAD binding proteins, transferases, and oxidoreductases. We identified 10 putative SMB clusters (Figure 5). A typical SMB cluster is formed by $3-6$ genes, with 1 or 2 PKS or NRPS genes, and other metabolite syntheses related genes.

\section{Evolutionary selection of CDC genes and domains}

To estimate selection on CDC and EC genes, $\mathrm{Ka} / \mathrm{Ks}$ ratios were calculated, with the assumption that genes with $\mathrm{Ka}>\mathrm{Ks}$ were likely under positive selection, genes with $\mathrm{Ka}=\mathrm{Ks}$ were likely evolving neutrally, and genes with $\mathrm{Ka}<\mathrm{Ks}$ were likely under purifying (negative) selection. Twenty-eight CDC and 6,036 EC genes were successfully aligned to A. brassicicola genes and Ka and Ks values were calculated for each. It was observed CDC genes had about a double $\mathrm{Ka}(0.08 / 0.043)$ and larger $\mathrm{Ka} /$ Ks ratios (0.133/0.084) than EC genes (Figure 6), possibly indicating greater positive selection on CDC genes. The two $\mathrm{CDC}$ genes with highest $\mathrm{Ka} / \mathrm{Ks}$ ratio was $\mathrm{CDC}_{-} 102$ (PKSs) and CDC_146 (phosphotransferase). However, no $\mathrm{CDC}$ genes showed $\mathrm{Ka} / \mathrm{Ks}>1$, suggesting that in these two Alternaria species strong positive selection may only occur in specific regions of a protein. The selection ratio only at conserved domains of CDC genes was then 


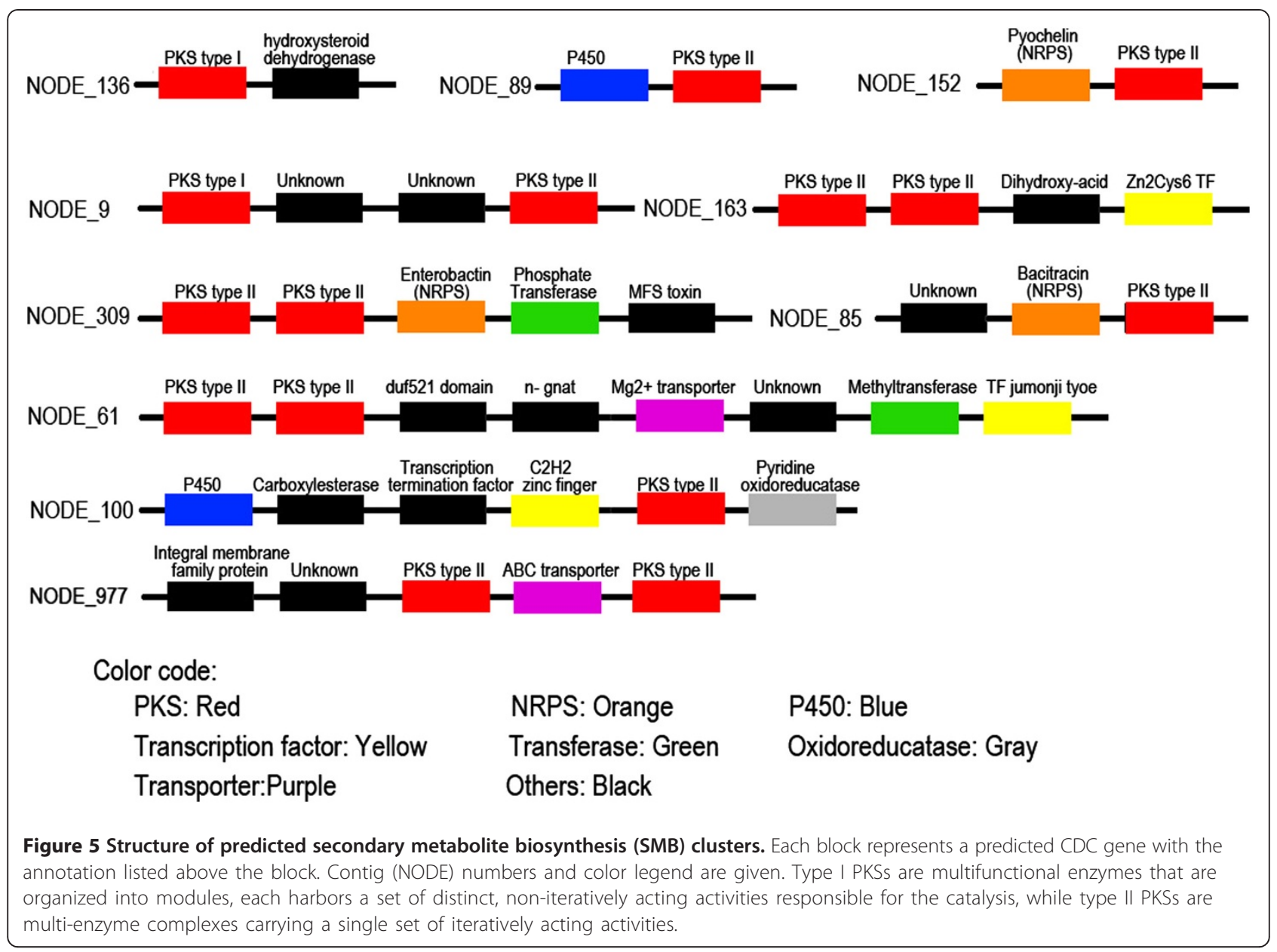

estimated. Domains of aligned CDC genes were identified using the NCBI CDD database. Each individual domain was extracted then the $\mathrm{Ka} / \mathrm{Ks}$ ratio was calculated and compared to that from same full length protein (Additional file 1: Table S5). We found two domains from $\mathrm{CDC} \_151$ with a higher $\mathrm{Ka} / \mathrm{Ks}$ ratio compared to whole length protein: a $12 x$ increase for the haloacid dehalogenase-like hydrolases (HAD_like) domain, which uses a nucleophilic aspartate in their phosphoryl transfer reaction, and $2 \mathrm{x}$ increase for heavy-metal-associated (HMA) domain, which transports or detoxifies heavy metals. Another interesting example was CDC_144, whose domain patatin-like phospholipase (Pat17, belonging to the alpha-beta hydrolase family) showed a $1.5 \mathrm{x}$ increase compared to whole length protein.

\section{Origin of CDC}

In the taxonomy report of CDC BLAST results, top hits came primarily from closely related dothideomycete fungi, indicating $\mathrm{CDC}$ may have fungal origin, or a transfer event occurred between CDC content and one or more fungal genomes. To test whether CDCs have the same phylogenetic placement with ECs, a phylogenetic analysis was conducted, including $\mathrm{EC}$ and $\mathrm{CDC}$ genes from $A$. arborescens, genes from $A$. brassicicola, and from three other ascomycete species: $P$. tritici-repentis, L. maculans, and A. oryzae. Proteins coded by 6 genes showing homology in all 6 groups were used to build a distance tree (Figure 7) using the neighbor-joining method [57]. Results show the CDC clade was within but basal to the two Alternaria clades.

A BLAST score ratio (BSR) [58] analysis was performed to test whether individual proteins on the $A$. arborescens $\mathrm{CDC}$ had more similarity to $A$. brassicicola or other fungi, and the result was compared with the same analysis to EC proteins. Complete genome protein sequences of three fungal species: $P$. tritici-repentis, $L$. maculans, and $A$. oryzae were extracted and built into a library called "3-fungi", representing proteins from closely related fungal species. Then proteins from the CDC and ECs were compared to the A. brassicicola protein library and "3-fungi" protein library respectively (Figure 8). It was clear, that there was less divergence between EC proteins and $A$. brassicicola proteins compared to that with other fungi $(35.5 \%$ vs $15.1 \%)$, consistent with the species phylogeny. In contrast, CDC 


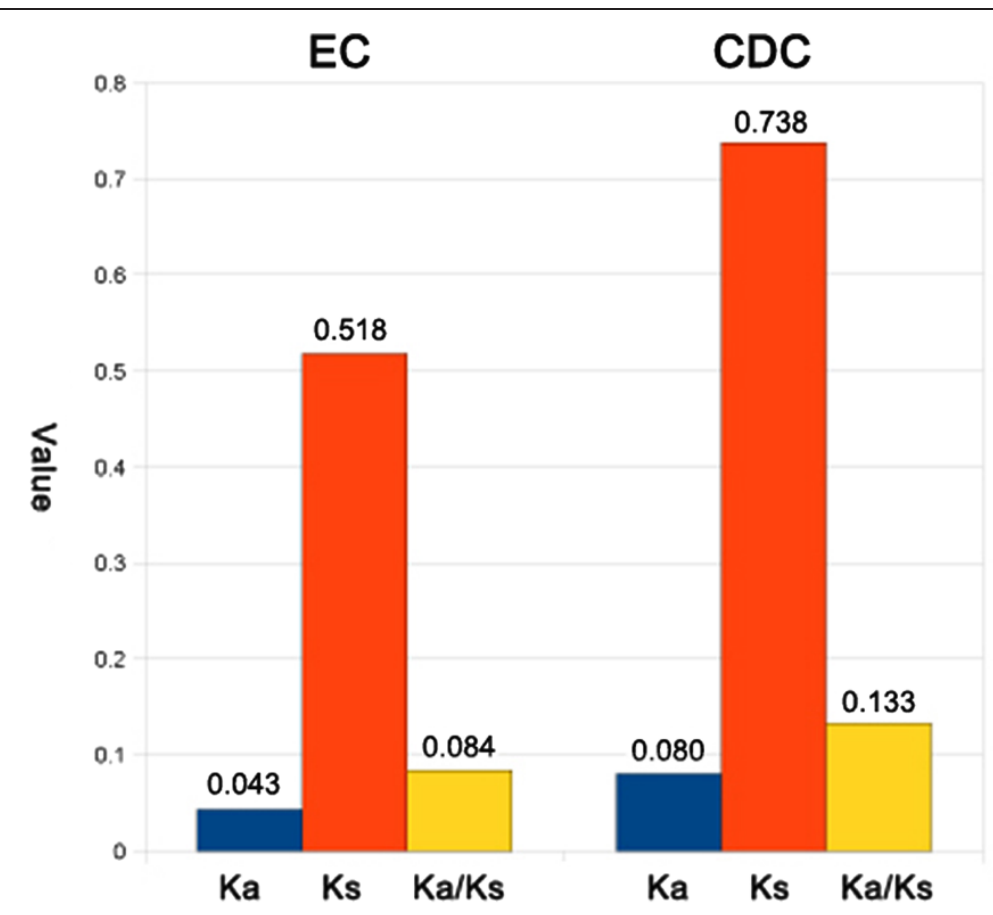

Figure 6 Average Ka/Ks ratio, Ka, and Ks for all aligned EC genes and CDC genes. 6323 EC proteins and 34 CDC proteins were involved and Codem program in the PAML suite was used (Capital "C", add "was").

proteins were more similar to proteins from other fungi $(16.7 \%$ vs 10.0\%), suggesting they have different evolutionary history other than EC proteins.

\section{Discussion}

\section{Comparison to other CDC containing fungi}

Compared to other recently published assemblies of CDCs in filamentous fungi, $A$. arborescens has a relatively small number of CDCs (one) and the size (1.0Mb) is small. $M$. graminicola was reported to have the highest number of dispensable chromosomes with upwards of 8 ranging in size from 0.39 to $0.77 \mathrm{MB}$ [59]. Three CDCs in $N$. haematococca $[9,60]$, and 4 complete CDCs and partial region of another 2 in F. oxysporum [7] were identified. In other Alternaria species, identified CDCs are relatively larger such as $1.05 \mathrm{Mb}$ in the strawberry pathotype [14], 1.1 to $1.7 \mathrm{Mb}$ (depending on strains) in the apple pathotype [13], and $4.1 \mathrm{Mb}$ in the Japanese pear pathotype $[61,62]$. In A. arborescens, only 1 dispensable chromosome is present, representing only $3 \%$ of the genome content, which is significantly smaller than other cases and may suggest a more recent acquisition or different origin.

\section{PKS and NRPS clusters}

Phytopathogenic fungi produce a diverse array of secondary metabolites, including host-selective toxins conferring

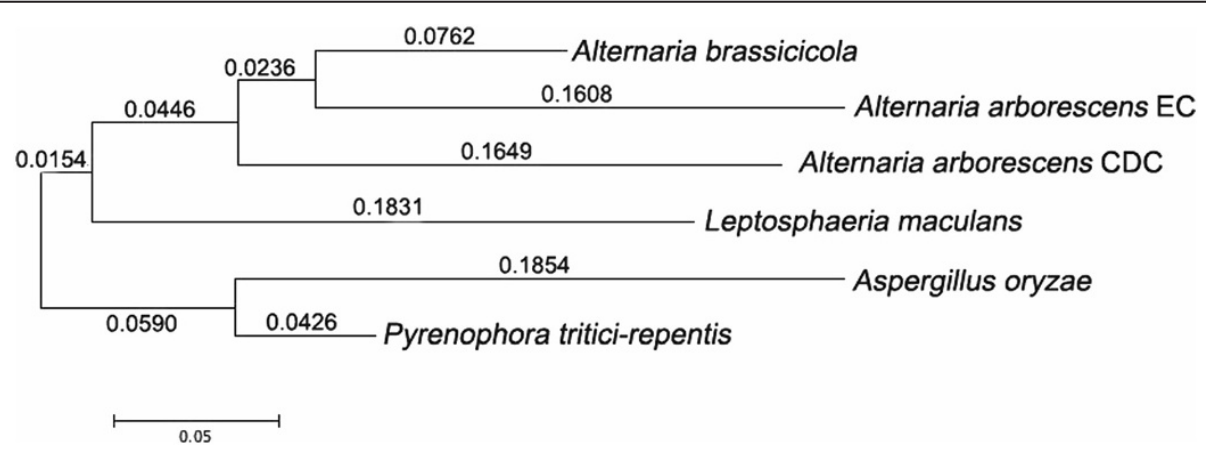

Figure 7 Phylogenetic relationship of proteins in A. arborescens CDC shows discordance compared to EC proteins. The phylogenetic distance tree was constructed by "MEGA 5 " using six protein sequences showing homology in all six groups. 

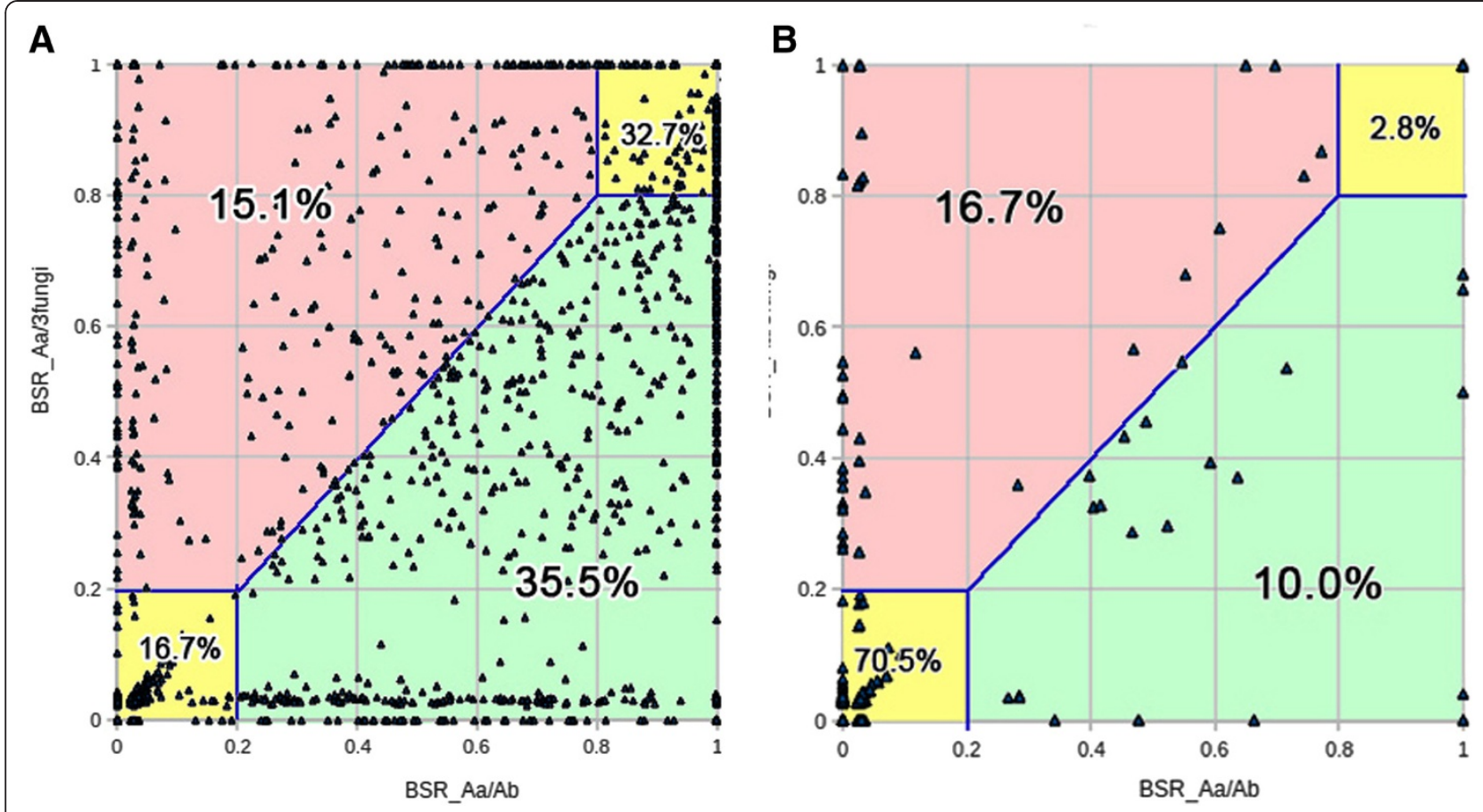

Figure 8 Scatter plots of BLAST Score Ratio (BSR) of EC proteins (A) and CDC proteins (B). The numbers in yellow regions indicate the percentage of genes that either lack homologous sequences (lower left corner) or contain homologous sequences in both $A$. brassicicola ( $A b$ ) library and 3-fungi library (upper right corner). The numbers in pink regions (upper left) indicate the percentage of genes with homologous sequences in 3-fungi library but not in Ab library, while numbers in green regions (lower right) indicate the percentage of genes with homologous sequences in the Ab library but not in the 3-fungi library.

pathogenicity [63]. It was reported in two basidiomycete maize pathogens candidate effector genes were located in small clusters that were dispersed throughout (both "are" change to "were") the genome [64]. However, in some other fungi, especially ascomycetes, genes coding for toxins can co-locate in clusters consisting of more than 10 contiguous genes. A well-known example is the trichothecene biosynthetic gene cluster in $F$. graminearum which contains 10-12 genes including a terpene synthase gene, P450 monooxygenase genes, acyl transferase genes, regulatory genes, and transporter genes [55]. While in $A$. fumigatus, 26 SMB clusters were identified, each containing 5-48 genes [65]. In our study, 29 PKS, 5 NRPS, and 2 hybrid PKS-NRPS genes were found on the CDC, with larger density compared to other fungi. However, among 10 predicted SMB clusters, most were relatively small and only carried 3-8 genes, which may not represent the true cluster size due to short contigs length that may divide one large cluster into two or more. One example of an identified cluster was located on contig Node_309 which consists of 5 genes, including 2 PKSs, 1 NRPS putatively coding for enterobactin, a phosphate transferase gene, and a MFS transporter. It lacks regulators, P450s, and transporters compared to other typical clusters. However, this cluster locates at the edge of the contig. Only 5 genes away from this cluster, another small cluster containing PKS, NRPS, P450s and an ABC transporter was identified, suggesting these two could be part of a larger cluster (see Additional file 3: Supplementary CDC annotation list). In this study, PKS genes were identified by screening the PKS sequence database, especially the domain database, which include: ketoacyl synthase (KS), acyl transferase (AT), ketoreductase (KR), dehydratase (DH), enoyl reductase (ER), and acyl carrier protein (ACP, also known as PP domain). The KS, AT, and ACP domains are essential for PKS genes [66]. Two PKS genes were identified to have multiple domains above: KS-AT-KR-ACP in CDC_141, and KS-AT-DH-ER-KR-ACP in CDC_165. The remaining 29 PKS genes each carries 1 or 2 ACP domains. Despite these conserved domains, other domains carried by these genes were divergent, indicating variance and multifunction of each PKS genes (Additional file 1: Table S6). However, at least 3 domain families were found to be enriched in the indentified PKS genes: $\mathrm{ABC}$ _membrane (4 identified), NADB_Rossmann (7 identified), and P-loop NTPase (6 identified), suggesting these proteins are transmembrane and catalyzing enzymatic reactions. In the NRPS and hybrid PKS-NRPS gene group, enterobactin, bacitracin, pyoverdine, syringomycin, and CDA1 domains were identified, 4 of which were reported from to bacteria 
[67-70]. We eliminated the possibility of these genes originating from bacterial sequencing contamination by BLAST comparing all assembly contig sequences against the NCBI All Bacterial database with 2017 genome sequences, and found that the species with most hits was Streptomyces coelicolor with $>80 \%$ identity. However, only $0.7 \%$ of the entire $S$. coelicolor genome was covered. Indicating that either these genes have an origin from bacteria or their product proteins interact with each other and require a highly conserved structure that was retained during evolution.

\section{Horizontal gene transfer}

According to the horizontal gene transfer hypothesis, A. arborescens may have acquired its CDC from another Alternaria species, from a fungus other than Alternaria, or possibly from a bacterium or virus [71]. There are at least two other possible explanations for its origin: (1) CDCs were present in an Alternaria ancestor, but were independently lost during vertical transmission in other non-pathogenic Alternaria species. (2) CDCs arose from essential chromosome as a copy first but then went under divergence so no obvious orthology could be detected. To test which of the three models fits this case best, we built a complete EC protein library and blasted all CDC proteins against it to detect any possible orthology. Out of 209 CDC proteins, we found 12 (5.7\%) showing orthology to EC proteins. Although the low orthology percentage alone could not exclude the "duplication and divergence" model, taken together with differences on GC3-content and codon usage bias, the possibility that this model fits is minimal.

To distinguish between HGT and vertical transmission hypothesis, we identified differences between $A$. arborescens CDC and EC genes in length, GC3-content, and codon usage bias. There was limited orthology detected between two groups; CDC genes showed discordant phylogenetic relation with $\mathrm{EC}$, and had higher similarity to other fungi than A. brassicicola. From previous phylogenetic analysis of 13 A. alternata isolates collected worldwide, CDC genes from different isolates were almost identical despite diverse EC background [41]. Taken these results together, we concluded that the HGT model may serve as the best fit model in this case. Additionally, these data support the theory proposed in 1983 by Nishimura that Alternaria species acquired HSTs by HGT [32].

In this study, we identified evidence for the possibility of HGT event occurred in A. arborescens. For Alternaria, this strategy has its advantages. First, as a pathogen with a wide host range, as observed in nature, transportable pathogenicity chromosome may increase pathogen's adaptation to environment. Second, loss of a CDC when there's no host may reduce the cost of carrying extra genome content. Third, as asexual fungi, horizontal transfer may compensate the lack of genetic recombination.

\section{Conclusions}

In this study, we identified $A$. arborescens CDC sequences through a whole genome sequencing and de-novo assembly process. By comparing nucleotide usage between $\mathrm{CDC}$ and EC contigs, we found evidence supporting HGT in $A$. arborescens. We also identified some predicted CDC genes under positive selection that may serve as virulence factors. However, questions still remain, such as the similarity and difference among CDCs from different $A$. arborescens isolates. To better understand $\mathrm{CDC}$ characteristics and mechanisms of HGT, other Alternaria isolates need to be sequenced.

\section{Materials and methods}

\section{Sequencing, assembly \& alignment}

A. arborescens DNA was extracted following a protocol described [72] and the sequencing library was prepared using the Illumina Paired-End DNA Sample Prep Kit. Sequencing was performed using Illumina Genome Analyzer II. Short reads were assembled de-novo using Velvet, and assembly quality was improved by a pipeline including two alternate assemblers: Edena [44], and Minimus2 [45]. Parameters including k-mer length for Velvet and hash length for Edena were optimized by sequential step changes. The alignment between A.arborescens and A.brassicicola was conducted using the Nucmer program in the MUMmer suite [46], with parameter $c=15$, $l=10$. Alignments with identities lower than $90 \%$ or lengths shorter than 100bp were removed.

\section{Southern hybridization}

On the CHEF gel membrane presented in Figure 2, lane 1 contains size markers, lane 2 contains $A$. arborescens chromosomes that had degraded, and lane 3 contains intact $A$. arborescens chromosomes. Southern hybridization was conducted using the GE health CDP-Star kit with 5 gene probes, including $1 \mathrm{CDC}$ marker gene $A L T 1,3$ predicted CDC genes, and 1 predicted EC gene. Primers (Additional file 1: Table S7) were designed using Primer3 [73] (v0.4.0). Blots were stripped between hybridizations to ensure no probes from previous hybridization remained. Film was exposed for 48 hours.

\section{Gene prediction, codon usage analysis \& repetitive DNA identification}

Gene prediction was conducted using FGENESH [47], an $a b$ initio gene predictor provided in the Softberry website. A pre-trained Alternaria matrix was used to optimize predictions. Both CDSs and protein sequences were generated and converted into fasta format files. ACUA [74] 
was used for calculating CAI and RSUC for each gene, and CAI distribution curves from the CDC group and EC group were compared to each other. Student's F-test was used to test statistical significance. RepeatScout [75] was used for de-novo identification of repeat sequences in both $\mathrm{CDC}$ and EC sequences. The repeat libraries were then aligned back to CDC and EC contigs using Nucmer to calculate the repeat percentage for each group.

\section{Gene annotation}

Blast2go [76] was used to annotate genes by "BLASTX" to the NCBI non-redundant protein database and then GO term assignment from the gene ontology database. Annotation of conserved domains was identified by scanning proteins through Pfam and NCBI CDD. PKS and NRPS genes were identified through scanning an online database SBSPKS [77]. The Fungal transcription factor database (FTFD) [78] was used to identify transcription factors. Transporters, P450s, and oxidoreducatases were identified based on BLAST and domain inspection. Potential secreted proteins were predicted using Signal 3.0 [79]. Pathogenicity and virulence factors were identified through scanning CDC genes in the pathogen-host interactions database (PHI-base) [54].

\section{Estimating $\mathrm{Ka} / \mathrm{Ks}$ Ratios}

A. arborescens proteins were blasted against A. brassicicola proteins to generate a match list between the two groups with a bits score cut-off at 300 . The gene sequences coding for aligned proteins were extracted by an in-house PERL script. Prank [80] was used to conduct codon alignment, in which two protein sequences were aligned first and then DNA sequences were aligned based on the corresponding protein alignments. The codon alignment result was then entered into "Codem" in PAML [81] (v4.0) for $\mathrm{Ka}$ and Ks calculation with model M0. In calculating, the Nei and Gojobori [82] method and Yang and Nielsen [83] method were used.

\section{Additional files}

\section{Additional file 1: Supplementary Tables contains: Table S1 to S7.}

Table S1: Velvet de-novo assembly statistics. Table S2: Repeat region

identification. Table S3: Codon usage correlation analysis. Table S4:

Differences in codon usage between CDC and EC genes. Table S5: Ka/Ks

ratio of CDC protein conversed domains. Table S6: Conserved domains in

CDC putative PKS genes. Table 57: Primers used for Southern

hybridization.

Additional file 2: Supplementary Figures contains: Figure S1 to S2.

Figure S1: Global contig alignment between A. arborescens contigs and A. brassicicola contigs. Figure $\mathrm{S} 2$ : GO term of CDC genes.

Additional file 3: CDC gene annotation list: a spreadsheet with all annotation information for all CDC genes.

\section{Abbreviations}

CDC: Conditionally dispensable chromosome; EC: Essential chromosome; PKS: Polyketide synthase; NRPS: Nonribosomal peptide synthetase; HST: Host specific toxin; HGT: Horizontal gene transfer; PFGE: Pulsed field gel electrophoresis; REMI: Restriction enzyme mediated integration; CHEF: Clamped homogenous electric fields; CAl: Codon adaptation index; RSCU: Relative synonymous codon usage; CDD: Conserved domains database; SMB: Secondary metabolite biosynthesis; BSR: Blast score ratio.

\section{Competing interests}

The authors declare that they have no competing interests.

\section{Authors' contributions}

$\mathrm{JH}$, genome assembly, annotation, analysis, and writing; CC, Southern hybridization and writing; TP, fungal isolate, CHEF gel membrane, and editing; HD, CL, assisted with assembly validation and editing; TM, conceived and designed study, analysis, and writing. All authors read and approved the final manuscript.

\section{Acknowledgements}

We are grateful to Dr. R.C. Venu at The Ohio State University (OSU) for preparing the sequencing library and the OSU Molecular Cellular Imaging Center (MCIC) for performing Illumina sequencing. We thank Drs. Kun Huang and Hideaki Kikuchi at the OSU Department of Biomedical Informatics for providing access to the high performance computing cluster. This work was supported by grant 2009-012 from the Ohio Agricultural Research and Development Center's Research Enhancement Competitive Grants Program (SEED).

\section{Author details}

'Department of Plant Pathology, The Ohio State University, Columbus, $\mathrm{OH}$ 43210, USA. ${ }^{2}$ Department of Plant Pathology, Washington State University, Pullman, WA 99164-6430, USA. ${ }^{3}$ Virginia Bioinformatics Institute, Virginia Polytechnic Institute and State University, Blacksburg, VA 24061, USA.

Received: 20 September 2011 Accepted: 8 March 2012

Published: 6 May 2012

\section{References}

1. Covert SF: Supernumerary chromosomes in filamentous fungi. Curr Genet 1998, 33(5):311-319.

2. VanEtten $H$, Jorgensen S, Enkerli J, Covert SF: Inducing the loss of conditionally dispensable chromosomes in Nectria haematococca during vegetative growth. Curr Genet 1998, 33(4):299-303.

3. Wilson EB: Studies on Chromosomes. V. The chromosomes of Metapodius. A contribution to the hypothesis of the genetic continuity of chromosomes. J Exp Zool 1909, 6:147-205.

4. Dean RA, Talbot NJ, Ebbole DJ, Farman ML, Mitchell TK, Orbach MJ, Thon M, Kulkarni $\mathrm{R}, \mathrm{Xu} J \mathrm{R}$, Pan $\mathrm{H}$, et al: The genome sequence of the rice blast fungus Magnaporthe grisea. Nature 2005, 434(7036):980-986.

5. Yoshida K, Saitoh H, Fujisawa S, Kanzaki H, Matsumura H, Tosa Y, Chuma I, Takano Y, Win J, Kamoun S, et al: Association genetics reveals three novel avirulence genes from the rice blast fungal pathogen Magnaporthe oryzae. Plant Cell 2009, 21(5):1573-1591.

6. Chuma I, Tosa Y, Taga M, Nakayashiki H, Mayama S: Meiotic behavior of a supernumerary chromosome in Magnaporthe oryzae. Curr Genet 2003, 43(3):191-198.

7. Ma L, van der Does HC, Borkovich KA, Coleman JJ, Daboussi MJ, Di Pietro A, Dufresne M, Freitag M, Grabherr M, Henrissat B, et al: Comparative genomics reveals mobile pathogenicity chromosomes in Fusarium. Nature 2010, 464(7287):367-373.

8. Han Y, Liu X, Benny U, Kistler HC, VanEtten HD: Genes determining pathogenicity to pea are clustered on a supernumerary chromosome in the fungal plant pathogen Nectria haematococca. Plant J: Cell Mol Biol 2001, 25(3):305-314.

9. Coleman JJ, Rounsley SD, Rodriguez-Carres M, Kuo A, Wasmann CC, Grimwood J, Schmutz J, Taga M, White GJ, Zhou S, et al: The genome of Nectria haematococca: contribution of supernumerary chromosomes to gene expansion. PLoS Genet 2009, 5(8):e1000618.

10. Stukenbrock EH, Jorgensen FG, Zala M, Hansen TT, McDonald BA, Schierup MH: Whole-genome and chromosome evolution associated with host adaptation and speciation of the wheat pathogen Mycosphaerella graminicola. PLoS Genet 2010, 6(12):e1001189. 
11. Tzeng $T H$, Lyngholm $L K$, Ford CF, Bronson CR: A restriction fragment length polymorphism map and electrophoretic karyotype of the fungal maize pathogen Cochliobolus heterostrophus. Genetics 1992, 130(1):81-96

12. Leclair S, Ansan-Melayah D, Rouxel T, Balesdent M: Meiotic behaviour of the minichromosome in the phytopathogenic ascomycete Leptosphaeria maculans. Curr Genet 1996, 30(6):541-548.

13. Johnson LJ, Johnson RD, Akamatsu H, Salamiah A, Otani H, Kohmoto K, Kodama M: Spontaneous loss of a conditionally dispensable chromosome from the Alternaria alternata apple pathotype leads to loss of toxin production and pathogenicity. Curr Genet 2001, 40(1):65-72.

14. Hatta R, Ito K, Hosaki Y, Tanaka T, Tanaka A, Yamamoto M, Akimitsu K, Tsuge $\mathrm{T}$ : A conditionally dispensable chromosome controls host-specific pathogenicity in the fungal plant pathogen Alternaria alternata. Genetics 2002, 161(1):59-70.

15. Rotem J: The Genus Alternaria. Biology, epidemiology, and pathogenicity. St. Paul: APS Press; 1994

16. Akamatsu H, Taga M, Kodama M, Johnson R, Otani H, Kohmoto K: Molecular karyotypes for Alternaria plant pathogens known to produce hostspecific toxins. Curr Genet 1999, 35(6):647-656.

17. Yasunori Akagi MT, Yamamoto Mikihiro, Tsuge Takashi, Fukumasa-Nakai Yukitaka, Otani Hiroshi, Kodama Motoichiro: Chromosome constitution of hybrid strains constructed by protoplast fusion between the tomato and strawberry pathotypes of Alternaria alternata. J Gen Plant Pathol 2009, 75(2):101-109.

18. Salamiah H, Yukitaka F, Hiroshi O, Motoichiro K: Construction and Genetic Analysis of Hybrid Strains between Apple and Tomato Pathotypes of Alternaria alternata by Protoplast Fusion. J Gen Plant Pathol 2001, 67(2):97-105.

19. Salamiah Y, Hajime A, Hiroshi O, Keisuke K, Motoichiro K: Genetic Analysis of Pathogenicity and Host-specific Toxin Production of Alternaria alternata Tomato Pathotype by Protoplast Fusion. I Gen Plant Pathol 2001, 67(1):7-14.

20. Masunaka A, Ohtani K, Peever TL, Timmer LW, Tsuge T, Yamamoto M, Yamamoto $\mathrm{H}$, Akimitsu K: An Isolate of Alternaria alternata That Is Pathogenic to Both Tangerines and Rough Lemon and Produces Two Host-Selective Toxins, ACTand ACR-Toxins. Phytopathology 2005, 95(3):241-247.

21. Nakatsuka S, Ueda K, Goto T, Yamamoto M, Nishimura S, Kohmoto K: Stucture of AF-toxin II, one of the host-specific toxins produced by Alternaria alternata strawberry pathotype. Tetrahedron Lett 1986, 27:2753-2756.

22. Nakashima T, Ueno T, Fukami H, Taga T, Masuda H, Osaki K, et al: Isolation and stuctures of AK-Toxin I and II, host-specific phytotoxic metabolites produced by Alternaria alternata Japanese pear pathotype. Agric Biol Chem 1985, 49:807-815.

23. Kohmoto $\mathrm{K}$, Itoh $\mathrm{Y}$, Shimomura N, Kondoh $\mathrm{Y}$, Otani $\mathrm{H}$, Kodama $\mathrm{M}$, et al: Isolation and biological activities of 2 host-specific toxins from the tangerine pathotype of Alternaria alternata. Phytopathology 1993, 83:495-502.

24. Feng BN, Nakatsuka S, Goto T, Tsuge T, Nishimura S: Biosynthesis of hostselective toxins produced by alternaria alternata pathogens, I: $(8 \mathrm{r}, 9 \mathrm{~s})$ 9,10-epoxy-8-hydroxy-9-methyl-deca-(2e,4z,6e)-trienoic acid as a biological precursor of AK-toxins. Agric Biol Chem 1990, 54:845-848.

25. Nakatsuka S, Feng BN, Goto T, Tsuge T, Nishimura S: Biosynthesis of HostSelective Toxins Produced by Alternaria-Alternata Pathogens .2. Biosynthetic Origin of (8r,9s)-9,10-Epoxy-8-Hydroxy-9-Methyl-Deca(2e,4z,6e)-Trienoic Acid, a Precursor of Ak-Toxins Produced by AlternariaAlternata. Phytochemistry 1990, 29(5):1529-1531.

26. Johnson RD, Johnson L, Itoh $Y$, Kodama M, Otani H, Kahmoto K: Cloning and characterization of a cyclic peptide synthetase gene from Alternaria alternata apple pathotype whose product is involved in AM-toxin synthesis and pathogenicity. Mol Plant Microbe Interact 2000, 13(7):742-753

27. Harimoto Y, Tanaka T, Kodama M, Yamamoto M, Otani H, Tsuge T: Multiple copies of AMT2 are prerequisite for the apple pathotype of Alternaria alternata to produce enough AM-toxin for expressing pathogenicity. J Gen Plant Pathol 2008, 74(3):222-229.

28. Syvanen M: Cross-species gene transfer; implications for a new theory of evolution. J Theor Biol 1985, 112(2):333-343.

29. Schmitt I, Lumbsch HT: Ancient horizontal gene transfer from bacteria enhances biosynthetic capabilities of fungi. PLoS One 2009, 4(2):e4437.

30. Richards TA, Dacks JB, Jenkinson JM, Thornton $C R$, Talbot NJ: Evolution of filamentous plant pathogens: gene exchange across eukaryotic kingdoms. Curr Biol 2006, 16(18):1857-1864.
31. Rosewich UL, Kistler HC: Role of Horizontal Gene Transfer in the Evolution of Fungi. Annu Rev Phytopathol 2000, 38:325-363.

32. Nishimura S, Kohmoto K: Host-Specific Toxins and Chemical Structures from Alternaria Species. Annu Rev Phytopathol 1983, 21:87-116.

33. Timothy F, Zhaohui L, Steven M, Hua L, Justin F, Jack R, Peter S, Bruce M, Richard O: Emergence of a new disease as a result of interspecific virulence gene transfer. Nat Genet 2006, 38:953-956.

34. Markham JE, Hille J: Host-selective toxins as agents of cell death in plantfungus interactions. Mol Plant Pathol 2001, 2(4):229-239.

35. Gilchrist DG, Grogan RG: Production and Nature of a Host-Specific Toxin from Alternaria-Alternata F-Sp Lycopersici. Phytopathology 1976, 66(2):165-171

36. Peever TL, Su G, Carpenter-Boggs L, Timmer LW: Molecular systematics of citrus-associated Alternaria species. Mycologia 2004, 96(1):119-134.

37. Akamatsu $\mathrm{H}$ : Molecular biological studies on the pathogenicity of Alternaria alternata tomato pathotype. J Gen Plant Pathol 2004, 70:389.

38. Yamagishi D, Akamatsu H, Otani $H$, Kodama M: Pathological evaluation of host-specific AAL-toxins and fumonisin mycotoxins produced by Alternaria and Fusarium species. J Gen Plant Pathol 2006, 72(5):323-327.

39. Akamatsu H, Otani H, Kodama M: Characterization of a gene cluster for host-specific AAL-toxin biosynthesis in the tomato pathotype of Alternaria alternata. Fungal Genet Newsl 2003, 50:355

40. Kroken S, Glass NL, Taylor JW, Yoder OC, Turgeon BG: Phylogenomic analysis of type I polyketide synthase genes in pathogenic and saprobic ascomycetes. Proc Natl Acad Sci U S A 2003, 100(26):15670-15675.

41. Akagi Y, Akamatsu H, Otani H, Kodama M: Horizontal Chromosome Transfer, a Mechanism for the Evolution and Differentiation of a PlantPathogenic Fungus. Eukaryot Cell 2009, 8(11):1732-1738.

42. Simmons EG: Alternaria themes and variations (236-243) - Host-specific toxin producers. Mycotaxon 1999, 70:325-369.

43. Zerbino DR, Birney E: Velvet: algorithms for de novo short read assembly using de Bruijn graphs. Genome Res 2008, 18(5):821-829.

44. Hernandez D, Francois P, Farinelli L, Osteras M, Schrenzel J: De novo bacterial genome sequencing: millions of very short reads assembled on a desktop computer. Genome Res 2008, 18(5):802-809.

45. Sommer DD, Delcher AL, Salzberg SL, Pop M: Minimus: a fast, lightweight genome assembler. BMC Bioinformatics 2007, 8:64.

46. Kurtz S, Phillippy A, Delcher AL, Smoot M, Shumway M, Antonescu C, Salzberg SL: Versatile and open software for comparing large genomes. Genome Biol 2004, 5(2):R12.

47. Salamov AA, Solovyev W: Ab initio gene finding in Drosophila genomic DNA. Genome Res 2000, 10(4):516-522.

48. Gojobori T, Bellgard Ml: Significant differences between the $\mathrm{G}+\mathrm{C}$ content of synonymous codons in orthologous genes and the genomic $\mathrm{G}+\mathrm{C}$ content. Gene 1999, 238(1):33-37.

49. Sharp PM, Li WH: The codon Adaptation Index-a measure of directional synonymous codon usage bias, and its potential applications. Nucleic Acids Res 1987, 15(3):1281-1295.

50. Sharp PM, Tuohy TM, Mosurski KR: Codon usage in yeast: cluster analysis clearly differentiates highly and lowly expressed genes. Nucleic Acids Res 1986, 14(13):5125-5143.

51. Bateman A, Coin L, Durbin R, Finn RD, Hollich V, Griffiths-Jones S, Khanna A, Marshall M, Moxon S, Sonnhammer EL, et al: The Pfam protein families database. Nucleic Acids Res 2004, 32(Database issue):D138-D141.

52. Marchler-Bauer A, Anderson JB, Cherukuri PF, DeWeese-Scott C, Geer LY, Gwadz M, He S, Hurwitz DI, Jackson JD, Ke Z, et al: CDD: a Conserved Domain Database for protein classification. Nucleic Acids Res 2005, 33(Database issue):D192-D196.

53. Ashburner M, Ball CA, Blake JA, Botstein D, Butler H, Cherry JM, Davis AP, Dolinski K, Dwight SS, Eppig JT, et al: Gene ontology: tool for the unification of biology. The Gene Ontology Consortium. Nat Genet 2000, 25(1):25-29.

54. Baldwin TK, Winnenburg R, Urban M, Rawlings C, Koehler J, HammondKosack KE: The pathogen-host interactions database (PHI-base) provides insights into generic and novel themes of pathogenicity. Mol Plant Microbe Interact 2006, 19(12):1451-1462.

55. Proctor RH, McCormick SP, Alexander NJ, Desjardins AE: Evidence that a secondary metabolic biosynthetic gene cluster has grown by gene relocation during evolution of the filamentous fungus Fusarium. Mol Microbiol 2009, 74(5):1128-1142.

56. $\mathrm{Yu} \mathrm{JH}$, Keller $\mathrm{N}$ : Regulation of secondary metabolism in filamentous fungi. Annu Rev Phytopathol 2005, 43:437-458. 
57. Saitou N, Nei M: The neighbor-joining method: a new method for reconstructing phylogenetic trees. Mol Biol Evol 1987, 4(4):406-425.

58. Parkinson J, Blaxter M: SimiTri-visualizing similarity relationships for groups of sequences. Bioinformatics 2003, 19(3):390-395.

59. Mehrabi R, Taga M, Kema GH: Electrophoretic and cytological karyotyping of the foliar wheat pathogen Mycosphaerella graminicola reveals many chromosomes with a large size range. Mycologia 2007, 99(6):868-876.

60. Miao VP, Covert SF, VanEtten HD: A fungal gene for antibiotic resistance on a dispensable ("B") chromosome. Science 1991, 254(5039):1773-1776.

61. Tsuge T, Tanaka A, Shiotani H, Yamamoto M: Insertional mutagenesis and cloning of the genes required for biosynthesis of the host-specific AKtoxin in the Japanese pear pathotype of Alternaria alternata. Mol Plant Microbe Interact 1999, 12(8):691-702.

62. Tsuge T, Tanaka A: Structural and functional complexity of the genomic region controlling AK-toxin biosynthesis and pathogenicity in the Japanese pear pathotype of Alternaria alternata. Mol Plant Microbe Interact 2000, 13(9):975-986.

63. Wolpert TJ, Dunkle LD, Ciuffetti LM: Host-selective toxins and avirulence determinants: what's in a name? Annu Rev Phytopathol 2002, 40:251-285.

64. Kamper J, Kahmann R, Bolker M, Ma LJ, Brefort T, Saville BJ, Banuett F, Kronstad JW, Gold SE, Muller O, et al: Insights from the genome of the biotrophic fungal plant pathogen Ustilago maydis. Nature 2006, 444(7115):97-101.

65. Nierman WC, Pain A, Anderson MJ, Wortman JR, Kim HS, Arroyo J, Berriman M, Abe K, Archer DB, Bermejo C, et al: Genomic sequence of the pathogenic and allergenic filamentous fungus Aspergillus fumigatus. Nature 2005, 438(7071):1151-1156.

66. Gokhale RS, Tuteja D: Biochemistry of polyketide synthases. Biotechnology 2001, 10:341-372

67. Dertz EA, Xu J, Stintzi A, Raymond KN: Bacillibactin-mediated iron transport in Bacillus subtilis. J Am Chem Soc 2006, 128(1):22-23.

68. Johnson BA, Anker H, Meleney FL: Bacitracin: A New Antibiotic Produced by a Member of the B. Subtilis Group. Science 1945, 102(2650):376-377.

69. Wendenbaum S, Demange P, Dell A, Meyer JM, Abdallah MA: The structure of pyoverdine $\mathrm{Pa}$, the siderophore of Pseudomonas aeruginosa. Tetrahedron Lett 1983, 24(44):4877-4880.

70. Scholz-Schroeder BK, Soule JD, Gross DC: The sypA, sypS, and sypC synthetase genes encode twenty-two modules involved in the nonribosomal peptide synthesis of syringopeptin by Pseudomonas syringae pv. syringae B301D. Mol Plant Microbe Interact 2003, 16(4):271-280

71. Lawrence CB, Mitchell TK, Craven KD, Cho Y, Cramer RA, Kim KH: At death's door: Alternaria pathogenicity mechanisms. J Plant Pathol 2008, 24(2):101-111.

72. Al-Samarrai $\mathrm{TH}$, Schmid J: A simple method for extraction of fungal genomic DNA. Lett Appl Microbiol 2000, 30(1):53-56.

73. Rozen S, Skaletsky H: Primer3 on the WWW for general users and for biologist programmers. Methods Mol Biol 2000, 132:365-386.

74. Vetrivel U, Arunkumar V, Dorairaj S: ACUA: a software tool for automated codon usage analysis. Bioinformation 2007, 2(2):62-63.

75. Price $A L$, Jones NC, Pevzner PA: De novo identification of repeat families in large genomes. Bioinformatics 2005, 21(Suppl 1):i351-i358.

76. Gotz S, Garcia-Gomez JM, Terol J, Williams TD, Nagaraj SH, Nueda MJ, Robles M, Talon M, Dopazo J, Conesa A: High-throughput functional annotation and data mining with the Blast2GO suite. Nucleic Acids Res 2008, 36(10):3420-3435.

77. Anand S, Prasad MV, Yadav G, Kumar N, Shehara J, Ansari MZ, Mohanty D: SBSPKS: structure based sequence analysis of polyketide synthases. Nucleic Acids Res 2010, 38(Web Server issue):W487-W496.

78. Park J, Jang S, Kim S, Kong S, Choi J, Ahn K, Kim J, Lee S, Park B, Jung K, et al: FTFD: an informatics pipeline supporting phylogenomic analysis of fungal transcription factors. Bioinformatics 2008, 24(7):1024-1025.

79. Bendtsen JD, Nielsen $H$, von Heijne G, Brunak S: Improved prediction of signal peptides: SignalP 3.0. J Mol Biol 2004, 340(4):783-795.

80. Loytynoja A, Goldman N: An algorithm for progressive multiple alignment of sequences with insertions. Proc Natl Acad Sci U S A 2005, 102(30):10557-10562

81. Yang Z: PAML 4: phylogenetic analysis by maximum likelihood. $\mathrm{Mol}$ Biol Evol 2007, 24(8):1586-1591.

82. Nei M: gT: Simple methods for estimating the numbers of syonymous and nonsynonymous nucleotide substitutions. Mol Biol Evol 1986, 3:418-426.
83. Yang Z, Nielsen R: Estimating synonymous and nonsynonymous substitution rates under realistic evolutionary models. Mol Biol Evol 2000 17(1):32-43.

doi:10.1186/1471-2164-13-171

Cite this article as: Hu et al:: Genomic characterization of the conditionally dispensable chromosome in Alternaria arborescens provides evidence for horizontal gene transfer. BMC Genomics 2012 13:171.

\section{Submit your next manuscript to BioMed Central and take full advantage of:}

- Convenient online submission

- Thorough peer review

- No space constraints or color figure charges

- Immediate publication on acceptance

- Inclusion in PubMed, CAS, Scopus and Google Scholar

- Research which is freely available for redistribution 